\title{
AS RELAÇÕES DE PODER, AS RELAÇÕES DE SENTIDO E A CULTURA NAS ORGANIZAÇÕES: UMA AVALIAÇÃO TEMPORAL COM REFLEXÕES E PERSPECTIVAS.
}

\author{
NILMAER SOUZA DA SILVA, JOANA SANCHES-JUSTO, VALDECIR CAHONI \\ Universidade do Oeste Paulista - UNOESTE
}

\section{RESUMO}

O ambiente organizacional requer dos gestores uma constante reflexão sobre premissas, paradigmas e estratégias para atuação no mercado, que é cada vez mais competitivo e tecnologicamente avançado. $O$ foco nas pessoas é a principal tática para que as empresas não só tenham um fragmento do mercado em que atuam, mas que desenvolvam diferencial competitivo. Diante disso, este trabalho apresenta uma analogia sobre o poder nas organizações, mostrando que este deve ser percebido como uma das principais fontes de controle nas instituições. Com base em fundamentações teóricas, percebe-se que o poder é cada vez menos explícito ao mesmo tempo em que é mais ideológico e situacional, ora requerendo imposição e outrora, a máxima flexibilidade para que possibilite relações de sentido.

PALAVRAS-CHAVE: poder, atores sociais, organizações, gestão, administração.

\section{INTRODUÇÃO E OBJETIVO}

Para analisar criticamente o poder nas organizações foi realizado um resgate conceitual de organização, cultura organizacional e, por fim, poder, para que se possa perfazer uma analogia sobre a influência do poder nas organizações como mecanismo de dominação e controle social.

Há de se salvaguardar que todas as organizações têm em seu interior características muito específicas que as diferenciam, inclusive, daquelas que pertençam a uma mesma categoria. Estas concepções e contextos sobre organizações evidenciam,claramente, que essas entidades têm objetivos definidos, cujo capital demandado para o seu alcance, é o intelectual, requerendo, por conseguinte, o estabelecimento de normas, princípios e regras, que formam a cultura da empresa ou organização, surgindo, a partir daí, o estabelecimento do poder, com base em tal cultura.

Ressalva-se que a cultura de uma organização, não é estática, quando são consideradas as influências internas e externas que essas entidades recebem constantemente. Como exemplo dos agentes influenciadores das organizações, citem-se os Stakeholders, que basicamente, são formados por: acionistas, clientes primários, fornecedores, comunidade, sindicatos, empregados, gerentes e não gerentes (HITT, 2003). Com referência às alusões acima, discute-se as relações de poder nas organizações, aqui, valendo-se de um marco - A era da Administração Científica, cujo fenômeno, para Chiavenatto (2004), é tido como revolução no pensamento administrativo, advindo logo após a revolução industrial. 
Desenvolve-se adiante, uma análise organizacional, partindo de uma reflexão teórica, e discute-se o estudo da administração, a partir de conceitos desenvolvidos por autores significativos da área que embasam o entendimento de como o poder era exercido em determinados períodos e contextos, diferido apenas por micro organismos, mas que, da sua essência, em nada muda.

\section{METODOLOGIA}

Este estudo teve caráter bibliográfico, resgatando autores consagrados para a discussão do panorama organizacional contemporâneo embasado por autores que abordam as relações de poder nas organizações e na sociedade. Os textos de autores como Chiavenato (2004), Borestain (2001) e Lévy (2001) forneceram embasamentos teóricos e dados bibliográficos que permitiram discussões acerca do tema proposto.

\section{RESULTADOS}

Segundo Chiavenato (2004) a Teoria Cientifica foi uma revolução no pensamento administrativo de sua época, em que a ênfase dos seus afazeres baseava-se nas tarefas e seu método de trabalho era a especialização do operário, que executava apenas uma tarefa, provocando mecanização e especialização em detrimento da elevação da produtividade e assim, em troca de seu esforço, havia um incentivo financeiro em forma de premiações, além da remuneração fixa.

Tal configuração faz surgir o "homem econômico", motivado a trabalhar somente por recompensas salariais, econômicas e materiais. O maior incentivo para continuar a batalha pelo trabalho é o medo da fome e a necessidade de dinheiro para se viver no ascendente mundo capitalista da época. Este posicionamento rígido, mecanicista e formal resulta na fadiga nos operários e consequentemente a diminuição da produtividade e qualidade do seu trabalho, gerando doenças, acidentes e incapacidade de esforço. Vê-se neste raciocínio que o poder é coercitivo e impositivo e, ainda, utiliza-se de ferramentas como recompensa e punição.

Cabe notar que, segundo Motta (1975), na mesma época em que se defendia a Administração Cientifica, o francês Henrri Fayol propôs que o ato de administrar deve estar apoiado em cinco funções básicas: prever, organizar, comandar, coordenar e controlar. Este entendimento da administração pode ser observado ainda hoje na estrutura administrativa. "Prever, significa ao mesmo tempo calcular o futuro e prepará-lo é, desde logo, agir" (PETER, 
1976, p. 58). Ao organizar as tarefas o administrador estará definindo cargos, e, ao alocar as pessoas na estrutura de cargos resultantes, o gestor define a estrutura do organismo social, isto é, quem está subordinado a quem, quem tem o poder de arbitrar decisões e quem deve obediência a quem.

O objetivo de Fayol era, portanto, a busca da eficiência das organizações, a participação do todo organizacional e de sua estrutura para garantir eficiência a todas as partes envolvidas, fossem elas departamentos, seções ou pessoas. Consigna-se, no postulado de Fayol, que o poder continua a ser explícito, haja vista, que a Administração da égide para a base é intensamente impositiva e qualquer esboço de criatividade esbarraria no pressuposto da unidade de direção das organizações, pela pirâmide organizacional.

Segundo Motta (1975), oposta à Teoria Clássica da Administração surgiu a Teoria das Relações Humanas, deslocando a ênfase na estrutura e nas tarefas para às pessoas, isto é, tornando mais humano o trabalho ao buscar satisfação das partes envolvidas no processo produtivo, todavia, não por caridade, mas sim, no intento de maximizar os ganhos nas diversas indústrias.

A Teoria das Relações Humanas abre a possibilidade de se criar uma cultura organizacional que propõe a identificação do indivíduo com a organização - com a finalidade de prendê-los totalmente nas malhas que ela tece, já que à medida que o indivíduo se identifica com a organização e pensa, por meio dela, idealizando a empresa a ponto de sacrificar sua vida privada às metas que ela estabelece, ele aceita fazer parte de um sistema totalitário, o qual se torna o meio legitimador de sua existência. Isso significa que o indivíduo passa a ter sua vida girando em torno da empresa, o que, em certa medida, o tranquiliza e o faz agir (LÉVY, 2001).

A empresa (ou qualquer outra organização) quer, atualmente, encarnar a "instituição divina". O sagrado laicizado dá ao indivíduo o sentimento de se transcender, através de um projeto a concretizar, umideal a realizar, uma causa a defender. Promete-lhe alcançar um estado não conflitante da psique, uma plenitude que o protege de qualquer trabalho de luto, de perda e de sofrimento. Então, o indivíduo pode se considerar como um herói dos tempos modernos, inscrevendo-se no mito coletivo da organização"( LÉVY, 2001, p.46-47).

Para esse postulado, a motivação econômica é secundária na determinação do rendimento do trabalhador. Para ela, as pessoas são motivadas pela necessidade de reconhecimento, de aprovação social, e participação nas atividades dos grupos sociais nos quais convivem. 
Portanto, é a partir desse marco que as organizações começam a tomar corpo de uma gestão mais flexível, tido por muitos autores e pensadores da contemporaneidade, bem como a própria doutrina de gestão estratégica, como gestão mais producente do que as mais rígidas. Nesse contexto, veremos adiante, a relação interdependente de liderança, gerência e poder.

\section{DISCUSSÃO}

Contextualiza Botelho (1993) que um discurso sobre liderança e gerência começa e continua com um discurso sobre o poder, surgindo os seguintes questionamentos: o que é o poder? De que modo ele aparece e como se dá? Como se exerce o poder? A liderança ou a prática liderante se exerce sobre e a partir de um poder? Respondendo, o mesmo autor afirma que não há liderança sem poder assim como não há discurso sem fala.

Weber (citado por BORESTAIN, 2001) descreve o poder como a possibilidade de alguém impor a sua vontade sobre o comportamento de outras pessoas ou, de forma mais sucinta, é a capacidade de realizar ou afetar os resultados organizacionais. Percebe-se, portanto, que o poder caracteriza uma relação entre atores sociais, em que uma pessoa não é "poderosa" ou "sem poder" em geral, mas, somente em determinada relação, situação e grupo social. Pode-se afirmar, ainda, que ninguém é o pleno gerente da própria vida social, ou ainda, que nenhum indivíduo, é capaz de ser líder absoluto de todas as equipes as quais faça parte.

O poder nas organizações é concebido pela natureza dos atores organizacionais, quais sejam: funcionários, gerentes, sócios, fornecedores e clientes; pela burocracia, que impetra o impessoalismo nas organizações, fomentando o exercício implícito e simbólico do poder; pela democracia, o Empowerment - a delegação de poder e responsabilidades assumidas por diversos membros de uma mesma organização, outorgados por alguém, porém, ao final, todas vinculadas, chanceladas e contempladas por uma pessoa, que é o detentor maior do poder, um Chief Executive Officer (CEO), por exemplo.

\section{CONCLUSÃO}

Portando, observa-se que o poder nas organizações pode ser concebido de inúmeras maneiras e, em algumas organizações, por vários atores sociais ao mesmo tempo. Nota-se, ainda, que a instituição do poder é ditada e editada a cada período histórico, sendo no início da Administração como ciência, mais autocrática, coercitiva e ditatória e que, como passar do tempo, o poder foi tomando um corpo mais tênue, cada vez menos explícito, utilizado como fonte de 
controle dos indivíduos que ela, organização, compõe, tornando os ideais pessoais subjacentes aos das empresas.

O poder do Administrador vem à tona provocando a emergência de uma tomada de decisão, unilateral, às vezes, e desprezando aspectos sociais, em muitos casos sempre com a premissa de que "isto é para o bem da coletividade". Logo, esta ideia, leva à conclusão de que os fins justificam os meios. Em outros termos, ações como esta são legitimadas pelos próprios profissionais que fazem parte da instituição com ênfase, principalmente, dos agentes não atingidos por tais decisões.

Uma certeza agora pode ser impetrada: o fenômeno "poder" jamais se extinguirá, entretanto, a de salvaguardar que a gestão participativa nos âmbitos operacionais, táticos e estratégicos das empresas, tem se mostrado uma opção importante para o estímulo da criatividade, ressaltando que nenhuma partilha é tão perfeita a ponto de uma decisão grupal ser tomada sem que alguém com maior status, poder, autoridade ou mesmo, racionalidade maior, de as marcas finais, antecedendo determinadas tomadas de decisão.

Dessa forma, o Administrador deve estar consciente desse fenômeno, das novas transformações que a Administração atual requer para que este possa ser usado como ferramenta que agregue valores para a organização, junto a um processo que poderá transformá-lo no principal agente de mudanças e sucesso e, uma vez obtido tal sucesso, essa concepção do poder na organização poderá provocar mudanças na mentalidade dos gestores, na cultura organizacional, chegando aos lares dos funcionários, mudando toda sociedade a ela vinculada e o conceito pejorativo de poder. É, portanto, uma nova modalidade de responsabilidade que se encontra nas mãos dos grandes gestores das organizações.

Não é demais advertir que quanto maior for o nível de clareza, formação, conhecimento e identidade de propósitos dos funcionários para com determinada empresa, ter-se-á uma minimização do poder, porém, a mesma proporcionalidade inversa dar-se-á quando o grau de instrução dos colaboradores for menor. Como consequência, quanto mais próxima a supervisão, menos a iniciativa e criatividade reinarão, acarretando inércia, ou ainda, a impossibilidade de mudança em determinado processo ou procedimento.

Fica, portanto, a cargo de cada Administrador desenvolver ferramentas para lidar com o poder e o controle na organização e formas de instalá-las com, primordialmente, ética e respeito social, o que, gerido, deve acarretar evolução à organização, acionistas, profissionais e sociedade em geral. 
A ética vai envolver a percepção de que os indivíduos dentro da empresa buscam algo além da remuneração, desejam o reconhecimento, buscam a afirmação ou identificação, ainda que não tenham claro o que isso significa (LÉVY, 2001). O Administrador, guiado pela ética, pode levar estes indivíduos a posicionarem-se frente à organização, descobrindo seu papel dentro da empresa e como se encaixam dentro de sua dinâmica de funcionamento.

A partir deste posicionamento, o Administrador pode, ao tornar as relações de poder menos rígidas, ajudar a organização a construir relações de sentido. Foucault (1984) diz que as relações de sentido são aquelas que permitem a alteridade, o colocar-se no lugar do outro e, desta forma, compartilharem suas visões de mundo. As relações de sentido fazem com que meros indivíduos se transformem em grupos, em pessoas que se unem porque juntas constroem leituras sobre o mundo e o cotidano e, também, sentidos para suas práticas de trabalho. Assim, à medida que o administrador maneja o grupo de forma que se estabeleça, além das relações de poder, relações de sentido, torna-se possível atingir um novo nível no potencial das relações de trabalho: o da alteridade e cooperação.

Então, uma forma de o administrador impulsionar uma transformação nas relações de poder e controle na organização que possa se estender à sociedade como um todo é incentivar que cada indivíduo tenha espaço e condições para se relacionar com o poder de forma menos encoberta ou idealizada, mostrando que idealizações são necessárias, mas que não podem assumir o caráter de definição da identidade do indivíduo, ou seja, as identificações não podem ser o ponto de apoio no qual este sustenta a sua vida.

Para que o indivíduo compreenda suas necessidades e desejos dentro da organização e, desse modo, estabeleça relações de sentido é necessário existir espaço para o questionamento e, também, para a angústia, o incômodo (LÉVY, 2001). Dessa forma, o sujeito estará menos alienado, menos subjugado e, assim, terá condições de contribuir efetivamente para a organização à medida que abandona a onipotência de acreditar que todos ao seu redor devem satisfazer seus desejos e necessidades e consegue se colocar no lugar do outro, desenvolvendo, assim, o clima de alteridade dentro da instituição. Desta maneira se tornarão funcionários capacitados a colaborar, produzir melhor, menos alienados porque sabem seus desejos, necessidades e seu lugar na organização. 


\section{REFERÊNCIAS}

BORESTAIN, Carlos Raul. Fatores intervenientes na mudança do sistema de poder. Dezembro 2001, disponível em <http://www.eps.ufsc.br>. Acesso em 01 Set.2006.

BOTELHO, Eduardo Ferreira. Do gerente ao líder: a evolução do profissional. 2a Edição, São Paulo: Atlas, 1993.

CHIAVENATO, Idalberto. Introdução à teoria geral da administração.7.ed. / rev. atual. 2.tir, Rio de Janeiro: Elsevier, c2004.

FOUCAULT, Michel. Verdade e Poder; Nietzsche, a genealogia e a história. In: Microfísica do Poder. 4a edição. Rio de Janeiro: Graal, 1984.

HITT, Michael; IRELAND, R. Duane, HOSKISSON, Robert. Administração estratégica competitividade e globalização. São Paulo: Pioneira Thomson Learning, 2003.

LÉVY, André et al. Psicossociologia: análise social e intervenção. Belo Horizonte: Autêntica, 2001.

MOTTA, Fernando C. Prestes. Teoria geral da Administração - uma introdução. 3ạ Edição, Biblioteca Pioneira de Administração Negócio, São Paulo: Pioneira, 1975.

PETER, M. Blau e W. Richard Scott. Administração Geral e Industrial. São Paulo: Ed. Atlas, 1976 